\title{
Predictive value of three Inflammation-based Glasgow Prognostic Scores for major cardiovascular adverse events in patients with acute myocardial infarction during hospitalization: a retrospective study
}

\author{
Houyong Zhu Equal first author, 1, 2, Zhaodong Li ${ }^{\text {Equal first author, } 3}$, Xiaoqun Xu ${ }^{3}$, Xiaojiang Fang ${ }^{2}$, Tielong Chen ${ }^{\text {Corresp., } 2}$, Jinyu \\ Huang Corresp. 4 \\ ${ }^{1}$ Department of Cardiology, Hangzhou Hospital of Traditional Chinese Medicine (Dingqiao District), Hangzhou, Zhejiang, China \\ Department of Cardiology, Hangzhou Hospital of Traditional Chinese Medicine (Wulin District), Hangzhou, Zhejiang, China \\ 3 Department of Clinical Laboratory, Hangzhou Red Cross Hospital, Hangzhou, Zhejiang, China \\ 4 Department of Cardiology, The Affiliated Hangzhou First People's Hospital, Zhejiang University School of Medicine, Hangzhou, Zhejiang, China \\ Corresponding Authors: Tielong Chen, Jinyu Huang \\ Email address: ctlppp@foxmail.com, hjyuo@foxmail.com
}

Aim: Inflammation-based Glasgow Prognostic Scores (GPS) have been reported to predict the prognosis of patients with acute ST-elevation myocardial infarction (STEMI) undergoing primary percutaneous coronary intervention (PPCl). The goal of this study was to investigate whether three kinds of GPSs can effectively predict major cardiovascular adverse events (MACEs) in STEMI or non-ST-segment elevation myocardial infarction (NSTEMI) patients undergoing $\mathrm{PPCl}$, elective $\mathrm{PCI}(\mathrm{EPCl}$ ) or conservative drug therapy during hospitalization.

Methods: In this retrospective cohort study, patients with acute myocardial infarction (AMI) were divided into 0, 1 or 2 score according to the GPSs. Logistic regression and receiver operating characteristic (ROC) curve analysis were performed to assess the predictive value of GPSs for MACE and all-cause mortality during hospitalization. Three kinds of GPSs, Inflammation-based Glasgow Prognostic Score (GPS), modified GPS (MGPS) and high-sensitivity CRP-modified GPS (HS-MGPS), and Global Registry of Acute Coronary Events (GRACE) score were applied in this study.

Results: A total of 188 patients were enrolled. The ROC curve with MACE showed that the AUC of GPS (0.820, [95\% confidence interval $(\mathrm{Cl}) 0.754-0.885], \mathrm{P}<0.001)$ was larger than that of MGPS $(0.789,[95 \%$ $\mathrm{Cl} 0.715-0.863], \mathrm{P}<0.001)$, HS-MGPS (0.787, [95\% Cl 0.717-0.856], $\mathrm{P}<0.001)$ and GRACE score $(0.743$, [95\% Cl 0.672-0.814], P $<0.001)$. The ROC curve with all-cause mortality showed that the AUC of GPS (0.696, [95\% Cl 0.561-0.831], $\mathrm{P}=0.005)$ was similar to the HS-MGPS $(0.698,[95 \% \mathrm{Cl} 0.569-0.826], \mathrm{P}=$ $0.005)$, and higher than the MGPS $(0.668,[95 \% \mathrm{Cl} 0.525-0.812], \mathrm{P}=0.016)$, but lower than the GRACE score $(0.812,[95 \% \mathrm{Cl} 0.734-0.889], \mathrm{P}<0.001)$. Multivariate logistic regression analysis showed that the GPS was an independent risk factor for the incidence of MACE during hospitalization. Compared with the odds ratio (OR) value for a GPS of 0 , the OR for a GPS of 1 was $7.173([95 \% \mathrm{Cl} 2.425-21.216], \mathrm{P}<0.001)$, and that for a GPS of 2 was 18.636 ([95\% Cl 5.813-59.746], $\mathrm{P}<0.001)$, but not an independent risk factor for all-cause mortality $(P=0.302)$. GRACE score was an independent risk factor for MACE (1.019, [95\% Cl 1.004-1.035], $\mathrm{P}=0.015)$ and all-cause mortality (1.040, [95\% Cl 1.017-1.064], $\mathrm{P}=0.001)$. In the subgroups classified according to the type of AMI, the presence of disease interference GPSs and the type of $\mathrm{PCl}$, the ability of GPS to predict the occurrence of MACE seemed to be greater than that of MGPS and HS-MGPS.

Peer] reviewing PDF | (2019:12:43760:1:1:NEW 25 Mar 2020) 
Conclusion: The GPS has a good predictive value for the occurrence of MACE during hospitalization in patients with AMI, regardless of STEMI or NSTEMI, the choice of PCI mode, and the presence or absence of diseases that interfere with GPS. However, GPS is less predictive of all-cause mortality during hospitalization than GRACE score, which may be due to the interference of patients with other diseases. 


\section{Manuscript Title}

2 Predictive value of three Inflammation-based Glasgow Prognostic Scores for major cardiovascular adverse events in 3 patients with acute myocardial infarction during hospitalization: a retrospective study

4 Houyong $\mathrm{Zhu}^{1,2^{*}}$, MD, Zhaodong $\mathrm{Li}^{3^{*}}$, MD, Xiaoqun $\mathrm{Xu}^{3}$, MD, Xiaojiang Fang ${ }^{2}$, MD, Tielong Chen² ${ }^{2 \#} \mathrm{PhD}$, Jinyu 5 Huang ${ }^{4 \prime}, \mathrm{PhD}$.

$6 *$ Contributed equally to this work.

$7{ }^{1}$ Department of Cardiology, Hangzhou Hospital of Traditional Chinese Medicine (Dingqiao District), Hangzhou, 8 Zhejiang, China

92 Department of Cardiology, Hangzhou Hospital of Traditional Chinese Medicine (Wulin District), Hangzhou, 10 Zhejiang, China

$11{ }^{3}$ Department of Clinical Laboratory, Hangzhou Red Cross Hospital, Hangzhou, Zhejiang, China

$12{ }^{4}$ The Affiliated Hangzhou First People's Hospital, Zhejiang University School of Medicine, Hangzhou, Zhejiang, 13 China

14 \#Corresponding author: Dr. Tielong Chen, Department of Cardiology, Hangzhou Hospital of Traditional Chinese

15 Medicine (Wulin District), Hangzhou, Zhejiang, China; Email: ctlppp@foxmail.com. Professor Jinyu Huang,

16 Department of Cardiology, The Affiliated Hangzhou First People's Hospital, Zhejiang University School of

17 Medicine, Hangzhou, Zhejiang, China; Email: hjyuo@foxmail.com. 
21 Abstract

Aim: Inflammation-based Glasgow Prognostic Scores (GPS) have been reported to predict the prognosis of patients with acute ST-elevation myocardial infarction (STEMI) undergoing primary percutaneous coronary intervention (PPCI). The goal of this study was to investigate whether three kinds of GPSs can effectively predict major cardiovascular adverse events (MACEs) in STEMI or non-ST-segment elevation myocardial infarction (NSTEMI) patients undergoing PPCI, elective PCI (EPCI) or conservative drug therapy during hospitalization.

Methods: In this retrospective cohort study, patients with acute myocardial infarction (AMI) were divided into 0, 1 or 2 score according to the GPSs. Logistic regression and receiver operating characteristic (ROC) curve analysis were performed to assess the predictive value of GPSs for MACE and all-cause mortality during hospitalization. Three kinds of GPSs, Inflammation-based Glasgow Prognostic Score (GPS), modified GPS (MGPS) and highsensitivity CRP-modified GPS (HS-MGPS), and Global Registry of Acute Coronary Events (GRACE) score were applied in this study.

Results: A total of 188 patients were enrolled. The ROC curve with MACE showed that the AUC of GPS $(0.820$, [95\% confidence interval (CI) 0.754-0.885], P < 0.001) was larger than that of MGPS $(0.789$, [95\% CI 0.715-0.863], $\mathrm{P}<0.001)$, HS-MGPS (0.787, [95\% CI 0.717-0.856], $\mathrm{P}<0.001)$ and GRACE score (0.743, [95\% CI 0.672-0.814], $\mathrm{P}<0.001)$. The ROC curve with all-cause mortality showed that the AUC of GPS (0.696, [95\% CI 0.561-0.831], P $=0.005)$ was similar to the HS-MGPS (0.698, [95\% CI 0.569-0.826], $\mathrm{P}=0.005)$, and higher than the MGPS $(0.668$, [95\% CI 0.525-0.812], $\mathrm{P}=0.016)$, but lower than the GRACE score $(0.812$, [95\% CI 0.734-0.889], $\mathrm{P}<0.001)$. Multivariate logistic regression analysis showed that the GPS was an independent risk factor for the incidence of MACE during hospitalization. Compared with the odds ratio (OR) value for a GPS of 0 , the OR for a GPS of 1 was 7.173 ([95\% CI 2.425-21.216], P < 0.001), and that for a GPS of 2 was 18.636 ([95\% CI 5.813-59.746], P $<0.001$ ), but not an independent risk factor for all-cause mortality $(\mathrm{P}=0.302)$. GRACE score was an independent risk factor for MACE (1.019, [95\% CI 1.004-1.035], $\mathrm{P}=0.015)$ and all-cause mortality (1.040, [95\% CI 1.017-1.064], $\mathrm{P}=0.001)$. In the subgroups classified according to the type of AMI, the presence of disease interference GPSs and the type of PCI, the ability of GPS to predict the occurrence of MACE seemed to be greater than that of MGPS and HS-MGPS.

Conclusion: The GPS has a good predictive value for the occurrence of MACE during hospitalization in patients with AMI, regardless of STEMI or NSTEMI, the choice of PCI mode, and the presence or absence of diseases that interfere with GPS. However, GPS is less predictive of all-cause mortality during hospitalization than GRACE score, which may be due to the interference of patients with other diseases.

Keywords: acute myocardial infarction; ST-elevation myocardial infarction; non-ST-segment elevation myocardial infarction; major cardiovascular adverse events; inflammation-based Glasgow Prognostic Scores; Global Registry of Acute Coronary Events (GRACE) score 


\section{Introduction}

54 Despite the development of percutaneous coronary intervention (PCI), coronary artery bypass grafts and 55 standardized revascularization strategies, acute myocardial infarction (AMI) is still one of the leading causes of 56 mortality worldwide. In Europe, unselected patients with AMI, especially ST-segment elevation myocardial 57 infarction (STEMI), still have a hospital mortality rate of $4 \%$ to $12 \%$ and an annual mortality rate of approximately $5810 \%[1]$. In the United States, STEMI patients have a hospital mortality rate of 5\%-6\% and an annual mortality rate 59 of 7\%-18\%[2]. However, in China, the mortality rate of AMI during hospitalization is higher than that in Europe and 60 the United States[3]. The efficient prediction and prevention of major adverse cardiovascular events (MACEs) are considered effective measures to avoid death outcomes[4]. Although age, heart failure, renal function and the number of coronary artery lesions can be used to predict the adverse outcomes of AMI, these indicators cannot clearly and intuitively evaluate the prognosis of AMI patients. The inflammation-based Glasgow Prognostic Score (GPS) makes use of the changes in albumin and hypersensitive C-reactive protein (H-CRP) to concisely evaluate the prognosis of cancer patients. In recent years, a retrospective study[5] showed that the ratio of H-CRP to albumin can predict the adverse outcome of patients with STEMI, and prospective cohort studies by Jia et al.[6] also indicated that the GPS also has a good predictive ability for the prognosis of STEMI patients undergoing primary PCI (PPCI). However, whether the GPS can effectively predict MACEs in STEMI or non-ST-segment elevation myocardial infarction (NSTEMI) patients undergoing PPCI, elective PCI (EPCI) or conservative drug therapy has not been reported. with two other modified GPSs for adverse events in patients with AMI during hospitalization.

\section{Materials and Methods}

\section{Subjects}

76 This was a single-center, retrospective cohort study designed to assess the predictive value of three GPSs for adverse 
77 events during hospitalization in patients with AMI undergoing PPCI, EPCI or conservative drug therapy. Patients

78 were recruited from the Department of Cardiovascular Disease of Hangzhou Hospital of Traditional Chinese Medicine from January 1, 2016, to July 24, 2019. This study belonged to retrospective cohort study, and the exemption of informed consent had been approved by the ethics committee of Hangzhou hospital of traditional Chinese medicine (Ethical Application Ref: 2019KY028). This study protocol strictly complied with the requirements of the Helsinki Declaration of the World Medical Association and the international ethics guide for human biomedical research of the Council for International Organizations of Medical Sciences (CIOMS).

\section{Patient Selection}

According to the results of the preliminary test, the optimal threshold was obtained through the Youden index, and the sensitivity of the best expectation was 0.862 , while the specificity of the best expectation was 0.714 . Finally, the estimation of the sample size of the diagnostic test was completed according to the expected sensitivity and specificity[7, 8], and its sample size was at least 184, which was calculated by MedSci Sample Size tools (MSST)(http://m.medsci.cn/sci/sample_size_diagnosisSamplerate.do).

According to the third global definition of myocardial infarction[9], a total of 188 patients met the inclusion criteria during the retrospective retrieval period. The exclusion criteria were as follows: (1) lack of data on H-CRP and serum albumin; (2) critical patients discharged automatically without MACEs; and (3) patients who lack or refuse to sign informed consent during hospitalization.

\section{Data Collection}

The baseline data included sex, age, diagnosis, Killip classification, MACE, PCI type, acute infection, autoimmune diseases, tumors, nephrotic syndrome, uremia, cirrhosis, hypertension, diabetes, blood pressure, ejection fraction (EF), and biochemical indicators including hemoglobin, platelet, type B natriuretic peptide (BNP), D-dimer, alanine aminotransferase (ALT), low density lipoprotein (LDL), creatinine, albumin, H-CRP, troponin I (TNI), creatine kinase $(\mathrm{CK})$ and creatine kinase $\mathrm{MB}(\mathrm{CK}-\mathrm{MB})$. All biochemical blood tests were performed in the laboratory for clinical purposes. All biochemical indicators were selected as the first biochemical results after admission. The GPS, 
102

103

104

105

106

107

modified GPS (MGPS), high-sensitivity CRP-modified GPS (HS-MGPS) and Global Registry of Acute Coronary Events (GRACE) score[10] were calculated. The score of GRACE was completed by reference to Granger CB et al[11-13]. In short, Killip classification, systolic blood pressure, heart rate, age, creatinine, and whether there was pre hospital cardiac arrest, ST segment down shift and myocardial enzyme elevation to form GRACE score. H-CRP and albumin were detected by latex particle-enhanced turbidimetric immunoassay and bromcresol green method, respectively. EF was detected by the M-type method and Simpson method. In addition, because the GPSs were composed of H-CRP and albumin, patients with acute infections, autoimmune diseases, tumors, nephrotic syndrome, uremia or liver cirrhosis were classified into the high tendency interference GPS group (HTI-GPS), and the rest were classified into the low tendency interference GPS group (LTI-GPS).

\section{Definition of GPS}

The definition of GPS was as follows: patients with an increased H-CRP level (>10 mg/L) and a low albumin level $(<35 \mathrm{~g} / \mathrm{L})$ are designated as having a GPS of 2 . The presence of one abnormality associated with either the H-CRP level or albumin level is designated as a GPS of 1 . If both indicators are normal, a GPS of 0 is designated.

The MGPS strengthens the position of H-CRP in the score, which is defined as follows: patients with an increased H-CRP level $(>10 \mathrm{mg} / \mathrm{L})$ and low albumin level $(<35 \mathrm{~g} / \mathrm{L})$ are designated as having an MGPS of 2. Patients with abnormal H-CRP levels are designated as having an MGPS of 1. As long as the H-CRP is not abnormal, it is designated as an MGPS of 0.

The HS-MGPS further strengthens the position of H-CRP in the score, which is defined as follows: patients with an increased H-CRP level $(>3 \mathrm{mg} / \mathrm{L})$ and low albumin level $(<35 \mathrm{~g} / \mathrm{L})$ are designated as having an HS-MGPS of 2. Patients with abnormal H-CRP levels are designated as having an HS-MGPS of 1. As long as the H-CRP is not abnormal, it is designated as an HS-MGPS of 0.

\section{Outcome Event}

Peer) reviewing PDF | (2019:12:43760:1:1:NEW 25 Mar 2020) 
126 The primary endpoint event was MACEs during hospitalization, which included cardiovascular death, deterioration

127 of heart failure, cardiogenic shock, mechanical complications of myocardial infarction, cerebral infarction,

128 myocardial reinfarction and persistent ventricular arrhythmia. The secondary endpoint event was all-cause mortality

129 during hospitalization.

\section{Statistical Analysis}

132

133

134

135

136

137

138

139

140

141

142

143

144

145

146

147

148

149

150

151
The data were analyzed using SPSS 25.0 (SPSS, Inc., Chicago, IL). Univariate analysis of continuous variables with normal distribution and equal variance was performed by one-way ANOVA. One-to-one comparisons were performed with the Student-Newman-Keuls test. When the variance was uneven, Dunnett's test was used for one-toone comparisons. Continuous variables of skewed distribution were first logarithmically transformed. If logarithmic data conformed to a normal distribution, the analysis was the same, but if they still did not conform to orthodox distribution, the median and quartiles were taken, and the Kruskal-Wallis test was used. The Pearson chi-square test or Fisher's exact test was used to analyze the rate according to the amount of data. Univariate/multivariate associations between clinical variables and in-hospital endpoints were estimated by logistic regression analysis with a forward stepwise logistic regression $(\mathrm{LR})$ model. The clinical variables in univariate analysis $(\mathrm{P}<0.10)$ and variables of clinical interest were included in multivariate analysis, but those variables that participated in the scoring system were excluded. In addition, in the logistic regression analysis, the variables with missing values were filled by the method of expectation maximization. The calibration of multivariate logistic regression model was evaluated by Hosmer-Lemeshow good of fit test. Receiver operating characteristic (ROC) curve analysis was performed, and the area under the curve (AUC) was calculated to determine the predictive ability of each score for the endpoint events. In addition, in subgroup analysis, the quantitative analysis of ROC curve comparison of three kinds of GPSs for MACEs prediction was completed by Delong method. The odds ratio (OR) (95\% confidence interval (CI)) and AUC (95\% CI), rate, rank sum number (RSN), median (quartile), mean \pm standard error (SE), and mean \pm standard deviation $(\mathrm{SD})$ were taken as statistical values in corresponding cases. A bilateral $\mathrm{P}<0.05$ was considered statistically significant.

Peer) reviewing PDF | (2019:12:43760:1:1:NEW 25 Mar 2020) 
152

153

154

155

156

\section{Results}

\section{Patient and Public Involvement}

Participants were not involved in the study design, recruitment, implementation, article writing or data collection. Patients did not incur additional medical burden in the study. The results of the study will be disseminated to all patients and medical institutions through academic conferences, news reports and health publicity.

\section{Baseline Patient Characteristics}

A total of 188 patients were included in the study (Fig. 1). The main clinical features of the patients are shown in Table 1. In summary, the average age was $68.21 \pm 14.89$ years, $77.7 \%$ of patients were male, and $71.8 \%, 42.6 \%$ and $38.8 \%$ of patients had hypertension, diabetes mellitus and HTI-GPS, respectively. Of these patients, 60 (31.9\%) had a MACE during hospitalization and 19 (10.1\%) had all-cause mortality during hospitalization. The baseline characteristics of patients were classified according to the grades of the three GPSs. Compared with the low-score group, the high-score group had older patients $(\mathrm{P}<0.001)$, a higher prevalence of diabetes $(\mathrm{P}<0.05)$, a higher HTIGPS rate $(\mathrm{P}<0.001)$, a lower diastolic blood pressure $(\mathrm{P}<0.05)$, higher Killip classes $(\mathrm{P}<0.001)$, lower hemoglobin levels $(\mathrm{P}<0.001)$, higher $\mathrm{D}$-dimer levels $(\mathrm{P}<0.001)$, higher creatinine levels $(\mathrm{P}<0.001)$ and higher BNP levels $(\mathrm{P}<0.001)$.

\section{Prediction of the Primary Endpoint Event}

The results of the ROC curve analysis for the incidence of MACE during hospitalization showed that the AUC value of the GPS $(0.820$, [95\% CI 0.754-0.885], $\mathrm{P}<0.001)$ was higher than that of the MGPS $(0.789$, [95\% CI $0.715-$ 0.863], $\mathrm{P}<0.001)$ (Fig. 2A), HS-MGPS (0.787, [95\% CI 0.717-0.856], $\mathrm{P}<0.001)$, GRACE score (0.743, [95\% CI 0.672-0.814], $\mathrm{P}<0.001)$, CK-MB level (0.485, [95\% CI 0.394-0.576], $\mathrm{P}=0.745)$, TNI level (0.593, [95\% CI 0.4480.629], $\mathrm{P}=0.394)$, LDL level $(0.440$, [95\% CI 0.346-0.534], $\mathrm{P}=0.193)$, and BNP level $(0.764$, [95\% CI 0.688 0.840], $\mathrm{P}<0.001)$. The predictive value of the H-CRP level $(0.809$, [95\% CI 0.747-0.871], $\mathrm{P}<0.001)$ and albumin level $(0.796$, [95\% CI 0.724-0.869], $\mathrm{P}<0.001)$ was also lower than that of the GPS. 


\section{Prediction of the Secondary Endpoint Event}

179 The results of the ROC curve analysis for the incidence of all-cause mortality during hospitalization indicated that the AUC value of the GPS $(0.696,[95 \%$ CI $0.561-0.831], \mathrm{P}=0.005)$ was similar to that of the HS-MGPS (0.698, [95\% CI 0.569-0.826], $\mathrm{P}=0.005)($ Fig. 2B) and BNP level (0.690, [95\% CI 0.562-0.818], $\mathrm{P}=0.009)$ and larger than that of the MGPS (0.668, [95\% CI 0.525-0.812], P=0.016), CK-MB level (0.461, [95\% CI 0.320-0.601], P=0.574),

TNI level (0.527, [95\% CI 0.389-0.665], P=0.701), LDL level (0.430, [95\% CI 0.269-0.592], P=0.332), and H-CRP level $(0.682$, [95\% CI 0.558-0.806], $\mathrm{P}=0.009)$ but smaller than that of the GRACE score $(0.812$, [95\% CI 0.7340.889], $\mathrm{P}<0.001)$ and albumin level $(0.724$, [95\% CI 0.585-0.863], $\mathrm{P}=0.001)$.

\section{Analysis of the Different Levels of GPSs}

Patients with a GPS of 2 had higher GRACE scores than those with a score of $1(17.15 \pm 6.01, \mathrm{P}=0.017)$ and 0 $(30.85 \pm 4.47, \mathrm{P}<0.001)$ (Fig. 3A). Patients with an MGPS of 2 also had higher GRACE scores than those with a score of $1(19.27 \pm 7.60, \mathrm{P}=0.044)$ and $0(28.40 \pm 4.28, \mathrm{P}<0.001)$ (Fig. 3B). Similarly, patients with an HS-MGPS of 2 also had higher GRACE scores than those with a score of $1(24.49 \pm 4.63, \mathrm{P}<0.001)$ and $0(28.12 \pm 5.94, \mathrm{P}<0.001)$ (Fig. 3C).

\section{Logistic Regression Analysis to Evaluate the GPS Risk in Endpoint Events}

The missing rates of LDL, D-dimer, BNP, EF (Simpson) and EF (M) were 1.1\%, 1.1\%, 13.8\%, 89.4\% and 52.1\% respectively(see Supplementary file 2). And in multivariate analysis, M-type method was used as EF measurement results to reduce the impact of too many missing values on the outcome.

Univariate logistic regression analysis showed that the incidence of MACE during hospitalization was positively correlated with the GPS ( $\mathrm{P}<0.001)$, and the GRACE score was also significant $(\mathrm{P}<0.001)$ (Table 2). 
204 for the incidence of MACE during hospitalization (1.019, [95\% CI 1.004-1.035], $\mathrm{P}=0.015)$. In addition, BNP and

205 TNI levels were also considered independent risk factors for MACE.

206 Univariate logistic regression analysis showed that all-cause mortality during hospitalization was positively

207 correlated with the GPS ( $\mathrm{P}=0.002)$, and the GRACE score was also significant $(\mathrm{P}<0.001)$ (Table 3). However,

208 multivariate logistic regression analysis $\left(\mathrm{P}_{\text {Hosmer-Lemeshow }}=0.351\right)$ showed that the GPS was not an independent risk

209 factor for all-cause mortality during hospitalization $(\mathrm{P}=0.302)$, but the GRACE score was (1.040, [95\% CI 1.017-

210 1.064], $\mathrm{P}=0.001)$. In addition, the type of PCI was shown to be an independent risk factor for all-cause mortality

211 during hospitalization (0.236, [95\% CI 0.089-0.625], $\mathrm{P}=0.004)$.

212

213 Subgroup Analysis

214 Subgroups were divided according to the type of AMI, the presence of disease interference GPSs and the type of

215 PCI. The prediction of MACE during hospitalization was assessed by ROC curve analysis. In the STEMI group, the

216 AUC value of the GPS (0.787, [95\% CI 0.688-0.887], P < 0.001) seemed to be larger than that of the MGPS $(0.740$,

217 [95\% CI 0.628-0.852], P < 0.001) and HS-MGPS (0.758, [95\% CI 0.656-0.861], P < 0.001) (Table 4), but Delong

218 test showed no significant statistical difference in the predictive value of the three scores (see Supplementary file 2).

219 In the NSTEMI group, the AUC value of the GPS $(0.855,[95 \%$ CI $0.772-0.938], \mathrm{P}<0.001)$ also seemed to be larger

220 than that of the MGPS (0.838, [95\% CI 0.746-0.931], P < 0.001) and HS-MGPS (0.812, [95\% CI 0.719-0.906], P <

221 0.001), but Delong test showed no significant statistical difference in the predictive value of the three scores. In the

222 HTI-GPS group, the AUC value of the GPS (0.711, [95\% CI 0.591-0.832], P=0.002) was similar to that of the

223 MGPS (0.717, [95\% CI 0.596-0.837], $\mathrm{P}=0.001)$ but seemed to be larger than that of the HS-MGPS (0.661, [95\% CI

224 0.534-0.787], $\mathrm{P}=0.018$ ). However, Delong test still showed that there was no significant statistical difference. In the

225 LTI-GPS group, the AUC value of the GPS (0.797, [95\% CI 0.679-0.915], P $<0.001)$ seemed to be larger than that

226 of the MGPS (0.702, [95\% CI 0.563-0.841], $\mathrm{P}=0.003)$ and HS-MGPS $(0.765$, [95\% CI 0.647-0.883], P < 0.001),

227 and Delong test showed that the predictive value of GPS was statistically different from that of MGPS. In the PPCI

228 group, the AUC value of the GPS $(0.800$, [95\% CI $0.707-0.893], \mathrm{P}<0.001)$ seemed to be larger than that of the

229

MGPS (0.756, [95\% CI 0.649-0.863], P < 0.001) and HS-MGPS (0.775, [95\% CI 0.682-0.868], P<0.001), but

230 Delong test showed that there was no statistical difference. In the EPCI group, the ROC curve analysis of the three

Peer) reviewing PDF | (2019:12:43760:1:1:NEW 25 Mar 2020) 
231 GPSs did not reach statistical significance. In the non-PCI group (conservative drug therapy), the AUC value of the 232 GPS (0.716, [95\% CI 0.532-0.900], P=0.030) was similar to that of the HS-MGPS (0.714, [95\% CI 0.533-0.896],

$233 \mathrm{P}=0.031)$ but seemed to be larger than that of the MGPS (0.692, [95\% CI 0.509-0.876], P=0.053), but Delong test

234 still showed that there was no significant statistical difference.

\section{Discussion}

237 This study investigated the predictive value of the three GPSs for the incidence of MACE and all-cause mortality in patients with AMI during hospitalization. The main findings are as follows. (1) The predictive ability of the GPS for the incidence of MACE during hospitalization was greater than that of the MGPS, HS-MGPS and GRACE score, and multiple logistic regression analysis showed that the GPS was an independent risk factor for the occurrence of MACE. (2) The three GPSs were less able to predict all-cause mortality during hospitalization than the GRACE score, and although they were risk factors for all-cause mortality in univariate logistic regression analysis, they were not independent risk factors for all-cause mortality in multiple logistic regression analysis. (3) In the subgroups classified according to the type of AMI, the presence of disease interference GPSs and the type of PCI, the ability of the GPS to predict the occurrence of MACE was generally greater than that of the MGPS and HS-MGPS.

In the long course of research on the pathogenesis of coronary atherosclerotic heart disease, the theory of inflammation, as one of the three theories, was first proposed by Virchow et al. in 1856. They believe that atherosclerosis is an inflammation of the intima of the arteries but is different from common inflammation. It starts with the deposition of CRP in the local area of atherosclerosis, which induces endothelial cells to secrete and express adhesion molecules and chemokines, promotes macrophages to express cytokines and tissue factors, and stimulates the uptake of LDL. It also stimulates macrophages to produce prothrombotic factors and endothelial cells and stimulates monocytes and lymphocytes to produce oxygen free radicals, which induces nuclear transcription factormediated arterial inflammation[14-17]. The Centers for Disease Control and Prevention and the American Heart Association (AHA) also suggested that CRP is one of the strongest predictors of cardiovascular disease. CRP of 3$10 \mathrm{mg} / \mathrm{L}$ suggests a high risk of AMI[18]. In addition to maintaining plasma osmotic pressure and acting as a carrier, 
258

259

260

261

262

263

264

265

266

267

268

269

270

271

272

273

274

275

276

277

278

279

280

281

282

283

284

cells[21-23]. Therefore, GPSs are structurally based on inflammation theory to predict the occurrence of MACE in patients with AMI.

In this study, we included three kinds of GPSs. The GPS first proposed by Forrest et al. was found to be able to predict the survival time of patients with non-small cell lung cancer[24]. Recent studies suggested that it has predictive value for the survival time of STEMI patients undergoing PPCI[6, 25]. The MGPS based on the GPS highlights the importance of CRP. The MGPS has been more widely used to assess the prognosis of patients with cancer than the GPS[26, 27], but the prognostic evaluation ability of patients with AMI is still unclear. In addition, the HS-MGPS based on the MGPS further highlights the importance of CRP, since the cut-off setting of CRP is equivalent to that in the high-risk group of AMI according to the guidelines of the AHA[18], which also implies that this score may be more accurate than the first two GPSs. However, our study found that the accuracy of the GPS in predicting MACE and all-cause mortality in patients with AMI during hospitalization was higher than that of the MGPS and HS-MGPS. In the subgroup analysis, in addition to the HTI-GPS, EPCI and conservative drug therapy groups, the ability of the GPS to predict MACE was still higher than that of the MGPS and HS-MGPS. The main difference between the GPS and the two improved scores is whether albumin can independently occupy 1 score in the GPS system, that is, the importance of albumin. In addition to the aforementioned inflammatory hypothesis based on albumin, patients with acute myocardial infarction are in a state of stress, with a significant increase in the basal metabolic rate, an increase in energy demand, changes in energy consumption pathways during stress, a limited use of glucose, and the use of albumin as an important energy source. The body relies on a large amount of protein decomposition to obtain energy, so the amount of serum albumin consumption also indirectly reflects the extent of AMI regarding the overall loss in patients. Studies have suggested that albumin levels are negatively correlated with the incidence of AMI[28, 29], and in patients with acute coronary syndrome (ACS), low albumin levels were found to be independent predictors of all-cause mortality and the deterioration of heart failure during hospitalization[30-32]. Therefore, the levels of albumin and CRP may be independent and equally important in predicting the prognosis of patients with AMI.

The secondary endpoint results showed that the three GPSs were less effective than the GRACE score in predicting all-cause mortality in patients with AMI during hospitalization. This may be due to the inclusion of patients in the real world who have many other diseases, such as diabetes, hypertension, and kidney disease. As a 
285

286

287

288

289

290

291

292

293

294

295

296

297

298

299

300

301

302

303

304

305

306

307

308

309

310

311

result, conditions affecting all-cause mortality can become very unpredictable and not limited to cardiovascular diseases based on the inflammation hypothesis. However, the components of the GRACE score include heart rate and systolic blood pressure as references. These values, as basic vital signs, can reflect the patient's response to all acute and severe diseases. Therefore, the predictive value of the GRACE score in predicting all-cause mortality is significantly higher than that of the GPSs. Considering the results of this study, our team speculated that although the GRACE score was better than the GPSs in predicting all-cause mortality, the GRACE score was also more affected by "interference factors" than the GPSs, so it may cause more false positives in predicting MACE, making its predictive ability less than that of the GPSs. Both the American College of Cardiology/AHA and the European Society of Cardiology guidelines recommend the GRACE score as one of the main criteria for the risk assessment of patients with $\mathrm{ACS}[33,34]$. It has a high predictive ability for hospitalization and provides a 5-year mortality risk for patients with ACS[35, 36]. Therefore, the GRACE score is considered to be an important predictor of mortality in ACS. However, there is no inflammatory component in its composition. According to the results of this study, if the GRACE score and GPS are combined, their prognostic value for patients with AMI may be improved.

The results of subgroup analysis showed that the predictive ability of the GPS for MACE occurrence seemed to be greater than that of the MGPS and HS-MGPS through ROC curve analysis in both the STEMI and NSTEMI groups, but due to the limitation of sample size, there was no statistical difference in quantitative comparison among these subgroups. There were many clinical factors that affect CRP and albumin levels, but the GPS had a good ability to predict MACE regardless of the presence of disease interference GPSs. In addition, in the PPCI and conservative drug therapy groups, the GPS still seemed to have a best ability to predict the occurrence of MACE compared with the modified GPSs, while in the EPCI group, none of the GPSs had meaningful predictive ability, but this may be due to the lack of data.

Patients with higher GPS scores may be accompanied by higher MACEs incidence than patients with lower scores. Strengthening the secondary prevention strategy of coronary heart disease and regular follow-up may be a good choice to prevent MACEs. In addition, anti-inflammatory treatment in the treatment strategy of coronary heart disease continues to experience a positive and negative process. In recent three large clinical trials, COLCOT study[37] and CANTOS study[38] showed the effectiveness and acceptability of anti-inflammatory treatment, but CIRT study[39] showed that anti-inflammatory treatment not only failed to reach positive end points, but also 
312 increased many adverse reactions. One of the possible reasons for the difference is that the baseline value of H-CRP

313 of the patients included in the first two studies is high, while the latter does not limit the value of H-CRP, which

314 results in the very low median value of H-CRP at the time of enrollment. This conjecture is also corresponding to

315 the results of our study, that is, the higher the GPS score, the higher the MACEs incidence. Therefore, the selection

316 of inflammatory indexes in anti-inflammatory treatment and the setting of cut-off value of intervention of these

317 indexes are likely to be the focus of future research.

318 In addition to the inflammatory hypothesis based GPS, prognostic nutritional index(PNI) was also reported to

319 have potential value in predicting adverse outcomes of pulmonary thromboembolism[40]. Therefore, in the future, combining the results of multiple prognosis scores may help patients with AMI to better avoid adverse outcomes.

There are some limitations to this study. First, it was a single-center, small-sample trial. Second, we only

322

323

324

325

326

327

328

329

330

331

\section{Conclusions} assess prognosis in patients with AMI during hospitalization and follow-up. 


\section{Acknowledgements}

340 This study was supported by the Science Technology Department of Zhejiang Province (2017C37130), and

341 Hangzhou Health Science and Technology Project (2017Z10). In addition, we thank MedSci

342 (https://www.medsci.cn/) for providing free sample size calculation tools for this study.

\section{References:}

346

1. Ibanez B, James S, Agewall S, Antunes MJ, Bucciarelli-Ducci C, Bueno H, Caforio A, Crea F, Goudevenos JA, Halvorsen S, Hindricks G, Kastrati A, Lenzen MJ, Prescott E, Roffi M, Valgimigli M, Varenhorst C, Vranckx P, Widimsky P. 2017 ESC Guidelines for the management of acute myocardial infarction in patients presenting with ST-segment elevation: The Task Force for the management of acute myocardial infarction in patients presenting with ST-segment elevation of the European Society of Cardiology (ESC). Eur Heart J. 2018 2018-01-07;39(2):119177.

2. O'Gara PT, Kushner FG, Ascheim DD, Casey DJ, Chung MK, de Lemos JA, Ettinger SM, Fang JC, Fesmire FM, Franklin BA, Granger CB, Krumholz HM, Linderbaum JA, Morrow DA, Newby LK, Ornato JP, Ou N, Radford MJ, Tamis-Holland JE, Tommaso CL, Tracy CM, Woo YJ, Zhao DX. 2013 ACCF/AHA guideline for the management of ST-elevation myocardial infarction: a report of the American College of Cardiology Foundation/American Heart Association Task Force on Practice Guidelines. J Am Coll Cardiol. 2013 2013-0129;61(4):e78-e140.

3. Chen WW, Gao RL, Liu LS, Zhu ML, Wang W, Wang YJ, Wu ZS, Li HJ, Gu DF, Yang YJ, Zheng Z, Jia LX, Hu SS. Summary of China Cardiovascular Disease Report 2016. Chinese Circulation Journal. 2017;32(6):521-530.

4. Shang P, Liu GG, Zheng X, Ho PM, Hu S, Li J, Jiang Z, Li X, Bai X, Gao Y, Xing C, Wang Y, Normand SL, Krumholz HM. Association Between Medication Adherence and 1-Year Major Cardiovascular Adverse Events After Acute Myocardial Infarction in China. J Am Heart Assoc. 2019 2019-05-07;8(9):e11793.

5. Çınar T, Çağdaş M, Rencüzoğulları İ, Karakoyun S, Karabağ Y, Yesin M, Sadioğlu Çağdaş Ö, Tanboğa Hİ. Prognostic efficacy of C-reactive protein/albumin ratio in ST elevation myocardial infarction. Scandinavian cardiovascular journal : SCJ. 2019 2019-04-01;53(2):83-90.

6. Jia Y, Li D, Cao Y, Cheng Y, Xiao L, Gao Y, Zhang L, Zeng Z, Wan Z, Zeng R. Inflammation-based Glasgow 
367

368

369

370

371

372

373

374

375

376

377

378

379

380

381

382

383

384

385

386

387

388

389

390

391

392

393

394

395

396

Prognostic Score in patients with acute ST-segment elevation myocardial infarction: A prospective cohort study. Medicine (Baltimore). 2018 2018-12-01;97(50):e13615.

7. Obuchowski NA, Zhou X. Prospective studies of diagnostic test accuracy when disease prevalence is low. Biostatistics (Oxford, England). 2002 2002-12-01;3(4):477-492.

8. Li J, Fine J. On sample size for sensitivity and specificity in prospective diagnostic accuracy studies. Stat Med. 2004 2004-08-30;23(16):2537-2550.

9. Thygesen K, Alpert JS, Jaffe AS, Simoons ML, Chaitman BR, White HD. Third universal definition of myocardial infarction. Glob Heart. 2012 2012-12-01;7(4):275-295.

10. Granger CB, Goldberg RJ, Dabbous O, Pieper KS, Eagle KA, Cannon CP, Van De Werf F, Avezum A, Goodman SG, Flather MD, Fox KA. Predictors of hospital mortality in the global registry of acute coronary events. Arch Intern Med. 2003 2003-10-27;163(19):2345-2353.

11. Granger CB, Goldberg RJ, Dabbous O, Pieper KS, Eagle KA, Cannon CP, Van De Werf F, Avezum A, Goodman SG, Flather MD, Fox KAA, Global ROAC. Predictors of hospital mortality in the global registry of acute coronary events. Archives of internal medicine. 2003 2003-10-27;163(19):2345-2353.

12. Fox KAA, Dabbous OH, Goldberg RJ, Pieper KS, Eagle KA, Van de Werf F, Avezum A, Goodman SG, Flather MD, Anderson FAJ, Granger CB. Prediction of risk of death and myocardial infarction in the six months after presentation with acute coronary syndrome: prospective multinational observational study (GRACE). BMJ (Clinical research ed.). 2006 2006-11-25;333(7578):1091.

13. Eagle KA, Lim MJ, Dabbous OH, Pieper KS, Goldberg RJ, Van de Werf F, Goodman SG, Granger CB, Steg PG, Gore JM, Budaj A, Avezum A, Flather MD, Fox KAA, GRACE I. A validated prediction model for all forms of acute coronary syndrome: estimating the risk of 6-month postdischarge death in an international registry. JAMA. 2004 2004-06-09;291(22):2727-2733.

14. Linden F, Domschke G, Erbel C, Akhavanpoor M, Katus HA, Gleissner CA. Inflammatory therapeutic targets in coronary atherosclerosis-from molecular biology to clinical application. Front Physiol. 2014 2014-01-20;5:455.

15. Lorenzatti AJ, Retzlaff BM. Unmet needs in the management of atherosclerotic cardiovascular disease: Is there a role for emerging anti-inflammatory interventions? Int J Cardiol. 2016 2016-10-15;221:581-586.

16. Ridker PM, Luscher TF. Anti-inflammatory therapies for cardiovascular disease. Eur Heart J. 2014 2014-0714;35(27):1782-1791.

17. Kottoor SJ, Arora RR. The Utility of Anti-Inflammatory Agents in Cardiovascular Disease: A Novel Perspective on the Treatment of Atherosclerosis. J Cardiovasc Pharmacol Ther. 2018 2018-11-01;23(6):483-493. 
397

398

399

400

401

402

403

404

405

406

407

408

409

410

411

412

413

414

415

416

417

418

419

420

421

422

423

424

425

426

427

18. Pearson TA, Mensah GA, Alexander RW, Anderson JL, Cannon RR, Criqui M, Fadl YY, Fortmann SP, Hong Y, Myers GL, Rifai N, Smith SJ, Taubert K, Tracy RP, Vinicor F. Markers of inflammation and cardiovascular disease: application to clinical and public health practice: A statement for healthcare professionals from the Centers for Disease Control and Prevention and the American Heart Association. Circulation. 2003 2003-01-28;107(3):499511.

19. Kawai Y, Masutani K, Torisu K, Katafuchi R, Tanaka S, Tsuchimoto A, Mitsuiki K, Tsuruya K, Kitazono T. Association between serum albumin level and incidence of end-stage renal disease in patients with Immunoglobulin A nephropathy: A possible role of albumin as an antioxidant agent. Plos One. 2018 2018-0120;13(5):e196655.

20. Rosas-Diaz M, Camarillo-Cadena M, Hernandez-Arana A, Ramon-Gallegos E, Medina-Navarro R. Antioxidant capacity and structural changes of human serum albumin from patients in advanced stages of diabetic nephropathy and the effect of the dialysis. Mol Cell Biochem. 2015 2015-06-01;404(1-2):193-201.

21. Lam FW, Cruz MA, Leung HC, Parikh KS, Smith CW, Rumbaut RE. Histone induced platelet aggregation is inhibited by normal albumin. Thromb Res. 2013 2013-07-01;132(1):69-76.

22. Fernandez J, Claria J, Amoros A, Aguilar F, Castro M, Casulleras M, Acevedo J, Duran-Guell M, Nunez L, Costa M, Torres M, Horrillo R, Ruiz-Del-Arbol L, Villanueva C, Prado V, Arteaga M, Trebicka J, Angeli P, Merli M, Alessandria C, Aagaard NK, Soriano G, Durand F, Gerbes A, Gustot T, Welzel TM, Salerno F, Banares R, Vargas V, Albillos A, Silva A, Morales-Ruiz M, Carlos GJ, Pavesi M, Jalan R, Bernardi M, Moreau R, Paez A, Arroyo V. Effects of Albumin Treatment on Systemic and Portal Hemodynamics and Systemic Inflammation in Patients With Decompensated Cirrhosis. Gastroenterology. 2019 2019-07-01;157(1):149-162.

23. Anraku M, Chuang VT, Maruyama T, Otagiri M. Redox properties of serum albumin. Biochim Biophys Acta. 2013 2013-12-01;1830(12):5465-5472.

24. Forrest LM, McMillan DC, McArdle CS, Angerson WJ, Dunlop DJ. Evaluation of cumulative prognostic scores based on the systemic inflammatory response in patients with inoperable non-small-cell lung cancer. $\mathrm{Br} \mathrm{J}$ Cancer. 2003 2003-09-15;89(6):1028-1030.

25. Wang R, Wen X, Huang C, Liang Y, Mo Y, Xue L. Association between inflammation-based prognostic scores and in-hospital outcomes in elderly patients with acute myocardial infarction. Clin Interv Aging. 2019 201901-20;14:1199-1206.

26. Wu CC, Li SH, Lu HI, Lo CM, Wang YM, Chou SY, Chen YH. Inflammation-based prognostic scores predict the prognosis of locally advanced cervical esophageal squamous cell carcinoma patients receiving curative concurrent chemoradiotherapy: a propensity score-matched analysis. Peerj. 2018 2018-01-20;6:e5655. 
428

429

430

431

432

433

434

435

436

437

438

439

440

441

442
27. Sato R, Oikawa M, Kakita T, Okada T, Abe T, Yazawa T, Tsuchiya H, Akazawa N, Sato M, Ohira T, Harada Y, Okano H, Ito K, Ohuchi N, Tsuchiya T. Preoperative change of modified Glasgow prognostic score after stenting predicts the long-term outcomes of obstructive colorectal cancer. Surg Today. 2019 2019-08-12.

28. He YM, Yang Q, Yang XJ, Zhao X, Xu HF, Qian YX. Serum albumin concentrations, effect modifiers and first incident acute myocardial infarction: A cross-sectional study of 1552 cases and 6680 controls. Clin Chim Acta. 2016 2016-02-15;454:49-56.

29. Djousse L, Rothman KJ, Cupples LA, Levy D, Ellison RC. Serum albumin and risk of myocardial infarction and all-cause mortality in the Framingham Offspring Study. Circulation. 2002 2002-12-03;106(23):2919-2924.

30. Xia M, Zhang C, Gu J, Chen J, Wang LC, Lu Y, Huang CY, He YM, Yang XJ. Impact of serum albumin levels on long-term all-cause, cardiovascular, and cardiac mortality in patients with first-onset acute myocardial infarction. Clin Chim Acta. 2018 2018-02-01;477:89-93.

31. Kurtul A, Murat SN, Yarlioglues M, Duran M, Ocek AH, Koseoglu C, Celik IE, Kilic A, Aksoy O. Usefulness of Serum Albumin Concentration to Predict High Coronary SYNTAX Score and In-Hospital Mortality in Patients With Acute Coronary Syndrome. Angiology. 2016 2016-01-01;67(1):34-40.

32. Gonzalez-Pacheco H, Amezcua-Guerra LM, Sandoval J, Martinez-Sanchez C, Ortiz-Leon XA, Pena-Cabral MA, Bojalil R. Prognostic Implications of Serum Albumin Levels in Patients With Acute Coronary Syndromes. Am J Cardiol. 2017 2017-04-01;119(7):951-958.

33. Anderson JL, Adams CD, Antman EM, Bridges CR, Califf RM, Casey DJ, Chavey WN, Fesmire FM, Hochman JS, Levin TN, Lincoff AM, Peterson ED, Theroux P, Wenger NK, Wright RS, Smith SJ, Jacobs AK, Adams CD, Anderson JL, Antman EM, Halperin JL, Hunt SA, Krumholz HM, Kushner FG, Lytle BW, Nishimura R, Ornato JP, Page RL, Riegel B. ACC/AHA 2007 guidelines for the management of patients with unstable angina/non-ST-Elevation myocardial infarction: a report of the American College of Cardiology/American Heart Association Task Force on Practice Guidelines (Writing Committee to Revise the 2002 Guidelines for the Management of Patients With Unstable Angina/Non-ST-Elevation Myocardial Infarction) developed in collaboration with the American College of Emergency Physicians, the Society for Cardiovascular Angiography and Interventions, and the Society of Thoracic Surgeons endorsed by the American Association of Cardiovascular and Pulmonary Rehabilitation and the Society for Academic Emergency Medicine. J Am Coll Cardiol. 2007 200708-14;50(7):e1-e157.

34. Bassand JP, Hamm CW, Ardissino D, Boersma E, Budaj A, Fernandez-Aviles F, Fox KA, Hasdai D, Ohman EM, Wallentin L, Wijns W. Guidelines for the diagnosis and treatment of non-ST-segment elevation acute coronary syndromes. Eur Heart J. 2007 2007-07-01;28(13):1598-1660.

Peer) reviewing PDF | (2019:12:43760:1:1:NEW 25 Mar 2020) 
459

460

461

462

463

464

465

466

467

468

469

470

471

472

473

474

475

476

477

478

479

480

481

482

483

484

485

35. Littnerova S, Kala P, Jarkovsky J, Kubkova L, Prymusova K, Kubena P, Tesak M, Toman O, Poloczek M, Spinar J, Dusek L, Parenica J. GRACE Score among Six Risk Scoring Systems (CADILLAC, PAMI, TIMI, Dynamic TIMI, Zwolle) Demonstrated the Best Predictive Value for Prediction of Long-Term Mortality in Patients with ST-Elevation Myocardial Infarction. Plos One. 2015 2015-01-20;10(4):e123215.

36. Fox KA, Carruthers KF, Dunbar DR, Graham C, Manning JR, De Raedt H, Buysschaert I, Lambrechts D, Van de Werf F. Underestimated and under-recognized: the late consequences of acute coronary syndrome (GRACE UKBelgian Study). Eur Heart J. 2010 2010-11-01;31(22):2755-2764.

37. Tardif J, Kouz S, Waters DD, Bertrand OF, Diaz R, Maggioni AP, Pinto FJ, Ibrahim R, Gamra H, Kiwan GS, Berry C, López-Sendón J, Ostadal P, Koenig W, Angoulvant D, Grégoire JC, Lavoie M, Dubé M, Rhainds D, Provencher M, Blondeau L, Orfanos A, L'Allier PL, Guertin M, Roubille F. Efficacy and Safety of Low-Dose Colchicine after Myocardial Infarction. The New England journal of medicine. 2019 2019-12-26;381(26):2497-2505.

38. Ridker PM, Everett BM, Thuren T, MacFadyen JG, Chang WH, Ballantyne C, Fonseca F, Nicolau J, Koenig W, Anker SD, Kastelein JJP, Cornel JH, Pais P, Pella D, Genest J, Cifkova R, Lorenzatti A, Forster T, Kobalava Z, Vida-Simiti L, Flather M, Shimokawa H, Ogawa H, Dellborg M, Rossi PRF, Troquay RPT, Libby P, Glynn RJ, CANTOS TG. Antiinflammatory Therapy with Canakinumab for Atherosclerotic Disease. The New England journal of medicine. 2017 2017-09-21;377(12):1119-1131.

39. Ridker PM, Everett BM, Pradhan A, MacFadyen JG, Solomon DH, Zaharris E, Mam V, Hasan A, Rosenberg Y, Iturriaga E, Gupta M, Tsigoulis M, Verma S, Clearfield M, Libby P, Goldhaber SZ, Seagle R, Ofori C, Saklayen M, Butman S, Singh N, Le May M, Bertrand O, Johnston J, Paynter NP, Glynn RJ, CIRT I. Low-Dose Methotrexate for the Prevention of Atherosclerotic Events. The New England journal of medicine. 2019 2019-02-21;380(8):752762.

40. Hayıroğlu Mİ, Keskin M, Keskin T, Uzun AO, Altay S, Kaya A, Öz A, Çinier G, Güvenç TS, Kozan Ö. A Novel Independent Survival Predictor in Pulmonary Embolism: Prognostic Nutritional Index. Clinical and applied thrombosis/hemostasis : official journal of the International Academy of Clinical and Applied Thrombosis/Hemostasis. 2018 2018-05-01;24(4):633-639.

\section{Figure legends}

Fig. 1 Flow diagram for recruitment of patients.

Fig. 2 ROC Curves of GPSs and GRACE score. A. Endpoint event with MACE. B. Endpoint event with all-cause mortality. $\mathrm{ROC}=$ receiver operating characteristic; GPSs = Inflammation-based Glasgow Prognostic Scores; GRACE = Global Registry of Acute Coronary Events; MACE = Global Registry of Acute Coronary Events; GPS = 
489 inflammation-based Glasgow Prognostic Score; MGPS = modified inflammation-based Glasgow Prognostic Score;

490 HS-MGPS = high-sensitivity CRP-modified inflammation-based Glasgow Prognostic Score; AUC = area under

491 the curve; $\mathrm{CI}=$ confidence interval. All values are represented as AUC (95\% CI).

492 Fig. 3 Relationship between the grade of GPSs and GRACE score. A. The grade of GPS and GRACE score. B. The 493 grade of MGPS and GRACE score. C. The grade of HS-MGPS and GRACE score. GPSs = Inflammation-based 494 Glasgow Prognostic Scores; GRACE = Global Registry of Acute Coronary Events; GPS = inflammation-based 495 Glasgow Prognostic Score; MGPS = modified inflammation-based Glasgow Prognostic Score; HS-MGPS = high496 sensitivity CRP-modified inflammation-based Glasgow Prognostic Score; SE = standard error. All values are 497 represented as mean $\pm \mathrm{SE} .{ }^{* *} P<0.001$ vs 0 or 1 score gourp. ${ }^{*} P<0.05$ vs 1 score gourp. ${ }^{\#} P<0.001$ vs 2 score 498 gourp. 
Figure 1

Fig. 1 Flow diagram for recruitment of patients.

Flow diagram for recruitment of patients. 
419 Patients were diagnosed with acute coronary syndrome

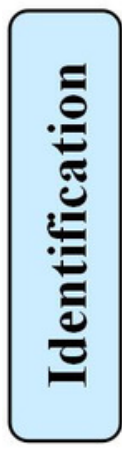

216 patients were excluded due to the final diagnosis of unstable angina pectoris

203 Patients were further screened

12 Patients were excluded due to lack of data or automatic discharge

191 patients were informed and signed informed consent

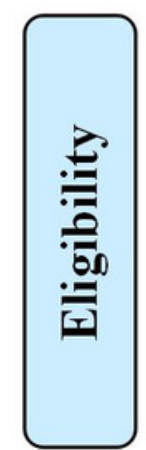

3 Patients were excluded due to refused to sign informed consent

188 Patients were recruited 
Figure 2

Fig. 2 ROC Curves of GPSs and GRACE score.

ROC Curves of GPSs and GRACE score. A. Endpoint event with MACE. B. Endpoint event with all-cause mortality. ROC $=$ receiver operating characteristic; GPSs = Inflammation-based Glasgow Prognostic Scores; GRACE = Global Registry of Acute Coronary Events; MACE = Global Registry of Acute Coronary Events; GPS = inflammation-based Glasgow Prognostic Score; MGPS = modified inflammation-based Glasgow Prognostic Score; HS-MGPS = highsensitivity CRP-modified inflammation-based Glasgow Prognostic Score; AUC = area under the curve; $\mathrm{Cl}=$ confidence interval. All values are represented as AUC $(95 \% \mathrm{Cl})$.
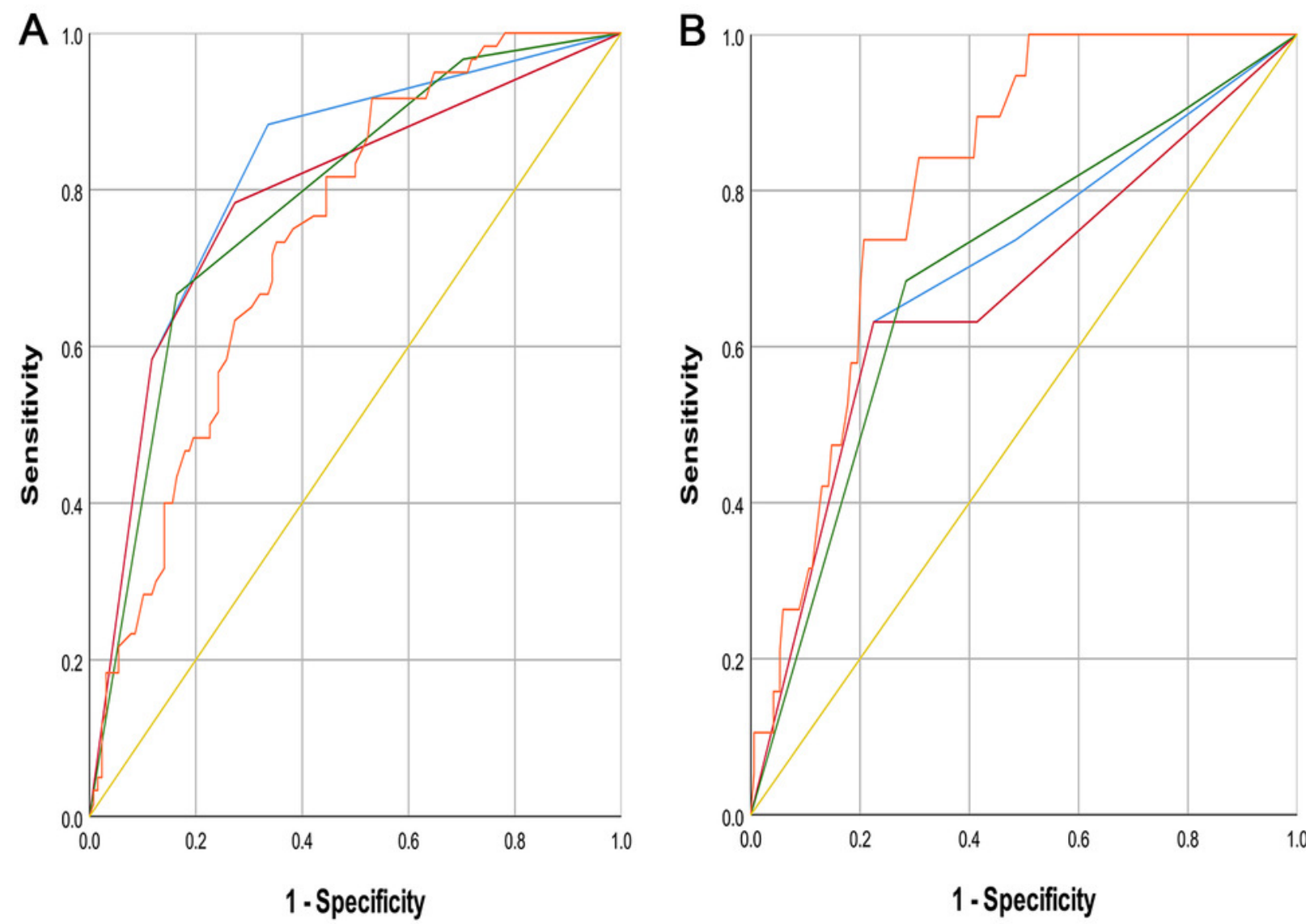

\section{Curve source \\ - GPS \\ - MGPS \\ - HS-MGPS \\ - GRACE score \\ - Reference line}

1-Specificity

1-Specificity 


\section{Figure 3}

Fig. 3 Relationship between the grade of GPSs and GRACE score.

Relationship between the grade of GPSs and GRACE score. A. The grade of GPS and GRACE score. B. The grade of MGPS and GRACE score. C. The grade of HS-MGPS and GRACE score. GPSs = Inflammation-based Glasgow Prognostic Scores; GRACE = Global Registry of Acute Coronary Events; GPS = inflammation-based Glasgow Prognostic Score; MGPS = modified inflammation-based Glasgow Prognostic Score; HS-MGPS = high-sensitivity CRP-modified inflammation-based Glasgow Prognostic Score; SE = standard error. All values are represented as mean $\pm \mathrm{SE} .{ }^{* *} P<0.001$ vs 0 or 1 score group. ${ }^{*} P<0.05$ vs 1 score gourp. ${ }^{\# \#} P$ $<0.001$ vs 2 score group.

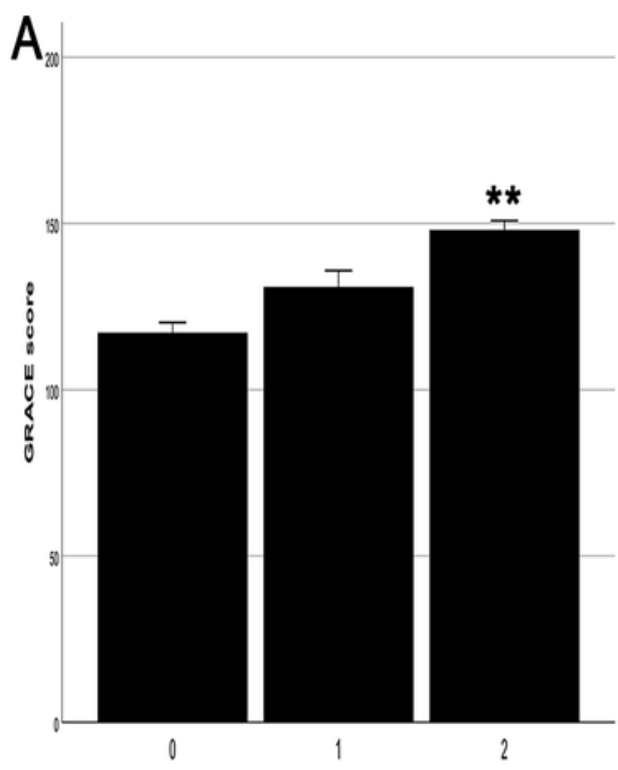

GPS
$\mathrm{B}_{2}$

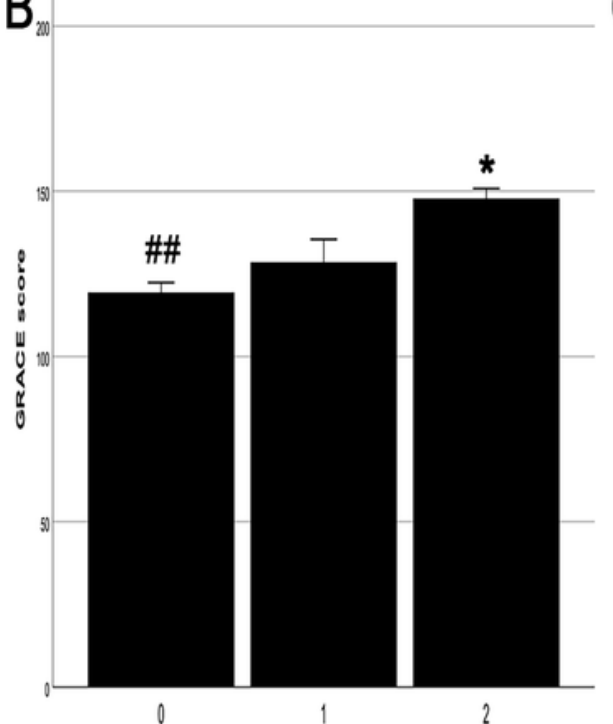

IIGPS
C

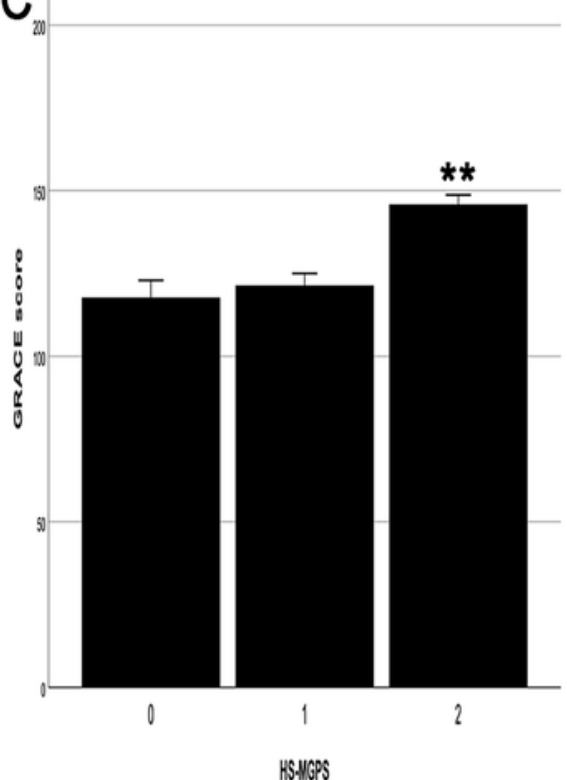

HSW HFS 


\section{Table $\mathbf{1}$ (on next page)}

Table 1 Relationships between clinical characteristics and the GPSs in patients with acute myocardial infarction.

Relationships between clinical characteristics and the GPSs in patients with acute myocardial infarction. GPSs = Inflammation-based Glasgow Prognostic Scores; GPS = inflammationbased Glasgow Prognostic Score; MGPS = modified inflammation-based Glasgow Prognostic Score; HS-MGPS = high-sensitivity CRP-modified inflammation-based Glasgow Prognostic Score; HTI-GPS = high tendency interference GPS group; SBP = systolic blood pressure; DBP $=$ diastolic blood pressure; $\mathrm{RSN}=$ rank sum number $\mathrm{EF}=$ ejection fraction; $\mathrm{ALT}=$ Alanine aminotransferase; $C K=$ creatine kinase; $C K-M B=$ creatine kinase $M B ; L D L=$ low density lipoproteincreatinine; $\mathrm{BNP}=$ type $\mathrm{B}$ natriuretic peptide; $\mathrm{TNI}=$ troponin $\mathrm{I} ; \mathrm{SD}=$ standard deviation. Except for rate and RSN, the rest are represented as mean \pm SD. 


\begin{tabular}{|c|c|c|c|c|c|c|c|c|c|c|c|c|}
\hline \multirow[b]{2}{*}{$\begin{array}{l}\text { Vairabl } \\
\text { e }\end{array}$} & \multicolumn{3}{|c|}{ GPS } & \multicolumn{4}{|c|}{ MGPS } & \multicolumn{5}{|c|}{ HS-MGPS } \\
\hline & 0 & 1 & 2 & $P$ & 0 & 1 & 2 & $P$ & 0 & 1 & 2 & $P$ \\
\hline $\begin{array}{l}\text { Age, } \\
\text { (years) }\end{array}$ & $\begin{array}{c}62.49 \pm 1 \\
5.05\end{array}$ & $\begin{array}{c}70.02 \pm 13 \\
.68\end{array}$ & $\begin{array}{c}77.06 \pm 10 \\
43\end{array}$ & $\begin{array}{l}<0 . \\
001\end{array}$ & $\begin{array}{c}63.83 \pm 1 \\
5.10\end{array}$ & $\begin{array}{c}69.03 \pm 14 \\
11\end{array}$ & $\begin{array}{c}77.06 \pm 10 \\
43\end{array}$ & $\begin{array}{l}<0 . \\
001\end{array}$ & $\begin{array}{c}63.51 \pm 1 \\
6.32\end{array}$ & $\begin{array}{c}64.95 \pm 1 \\
4.58\end{array}$ & $\begin{array}{c}68.21 \pm 14 \\
89\end{array}$ & $\begin{array}{l}<0 . \\
001\end{array}$ \\
\hline $\begin{array}{l}\text { Males, } \\
(\mathrm{n}, \%)\end{array}$ & $80(54.8)$ & $31(21.2)$ & $35(24.0)$ & $\begin{array}{c}0.0 \\
10\end{array}$ & $90(61.6)$ & $21(14.4)$ & $35(24.0)$ & $\begin{array}{l}0.0 \\
49\end{array}$ & $37(25.3)$ & $68(46.6)$ & $41(28.1)$ & $\begin{array}{l}0.0 \\
22\end{array}$ \\
\hline $\begin{array}{l}\text { Hyperte } \\
\text { nsion, } \\
(\mathrm{n}, \%)\end{array}$ & $62(45.9)$ & $33(24.4)$ & $40(29.6)$ & $\begin{array}{c}0.2 \\
80\end{array}$ & $75(55.6)$ & $20(14.8)$ & $40(29.6)$ & $\begin{array}{c}0.2 \\
69\end{array}$ & $25(18.5)$ & $60(44.4)$ & $50(37.0)$ & $\begin{array}{c}0.0 \\
59\end{array}$ \\
\hline $\begin{array}{l}\text { Diabetic } \\
\text { s, }(n, \%)\end{array}$ & $31(38.8)$ & $20(25.0)$ & $29(36.3)$ & $\begin{array}{l}0.0 \\
20\end{array}$ & $38(47.5)$ & $13(16.3)$ & $29(36.3)$ & $\begin{array}{l}0.0 \\
29\end{array}$ & $16(20.0)$ & $30(37.5)$ & $34(42.5)$ & $\begin{array}{l}0.0 \\
37\end{array}$ \\
\hline $\begin{array}{l}\text { HTI- } \\
\text { GPS, (n, } \\
\%)\end{array}$ & $8(11.0)$ & $23(31.5)$ & $42(57.5)$ & $\begin{array}{l}<0 . \\
001\end{array}$ & $13(17.8)$ & $18(24.7)$ & $42(57.5)$ & $\begin{array}{l}<0 . \\
001\end{array}$ & $3(4.1)$ & $23(31.5)$ & $47(64.4)$ & $\begin{array}{l}<0 . \\
001\end{array}$ \\
\hline
\end{tabular}

\footnotetext{
Heart

$\begin{array}{llllllllllllll}\text { rate, } \quad & 78.27 \pm 1 & 83.58 \pm 18 & 82.66 \pm 20 . & 0.1 & 78.96 \pm 1 & 83.77 \pm 17 . & 82.66 \pm 20 . & 0.1 & 74.02 \pm 1 & 82.28 \pm 1 & 83.05 \pm 20 & 0.0\end{array}$ $\begin{array}{lllllllllllll}\text { (times/ } & 5.80 & .53 & 11 & 74 & 6.58 & 61 & 11 & 74 & 1.34 & 7.47 & 66 & 22\end{array}$ $\min )$

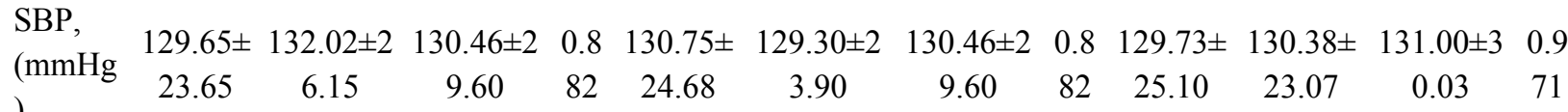

DBP,

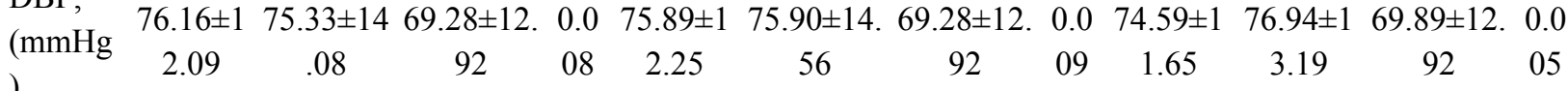
Killip $\begin{array}{lllllllllllll}\begin{array}{l}\text { classific } \\ \text { ation, }\end{array} & 75.34 & 105.04 & 120.06 & <0 . & 81.88 & 96.82 & 120.06 & <0 . & 79.55 & 83.62 & 119.89 & <0 \\ \text { (RSN) }\end{array}$ (RSN)
} 


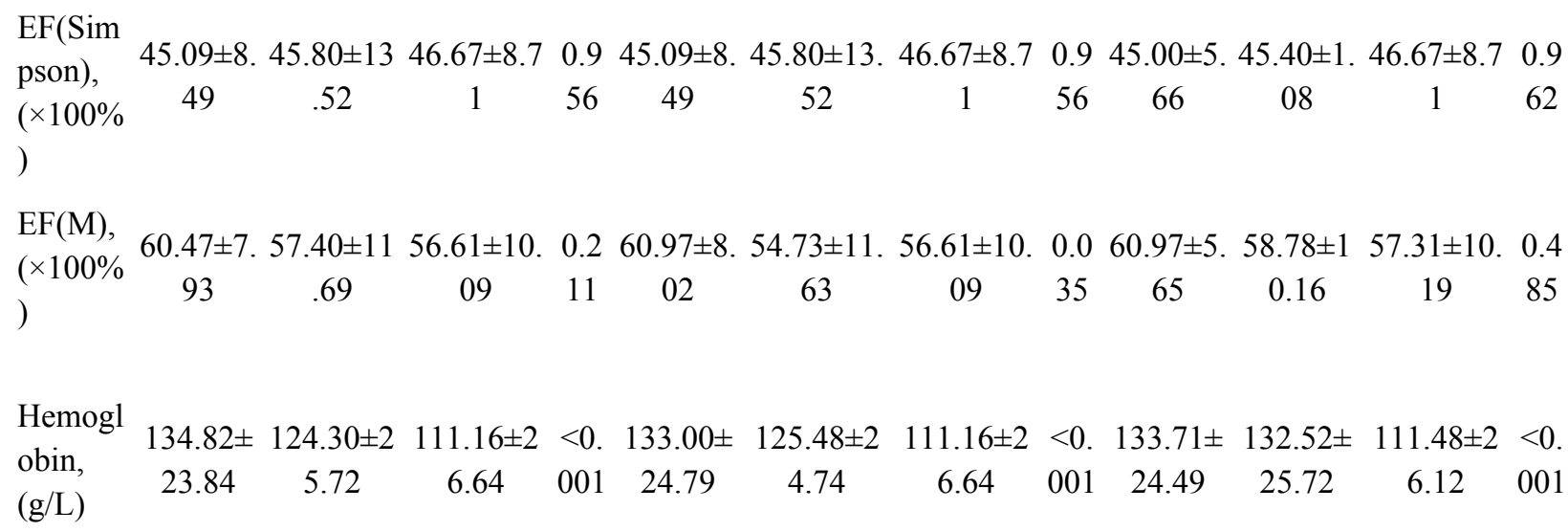

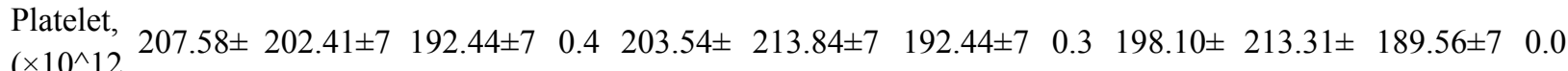

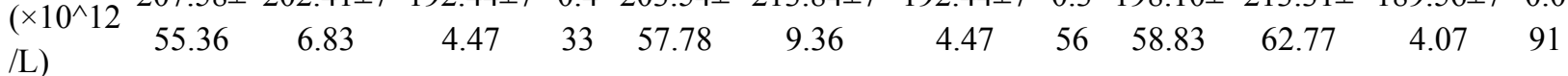

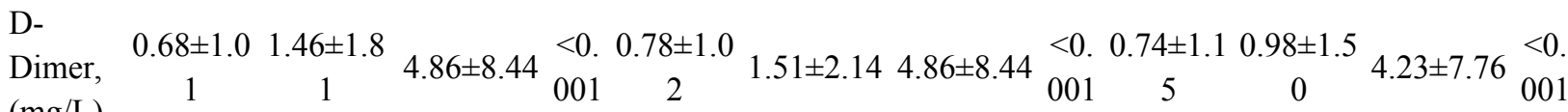
$(\mathrm{mg} / \mathrm{L})$

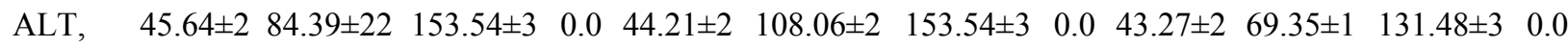

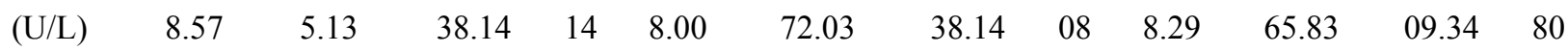

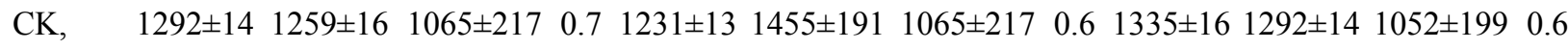
$\begin{array}{llllllllllll}(\mathrm{U} / \mathrm{L}) & 09 & 51 & 9 & 41 & 47 & 5 & 9 & 05 & 59 & 76 & 9\end{array}$

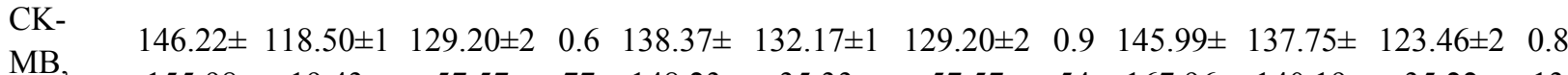

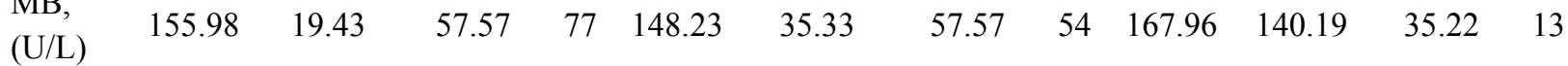

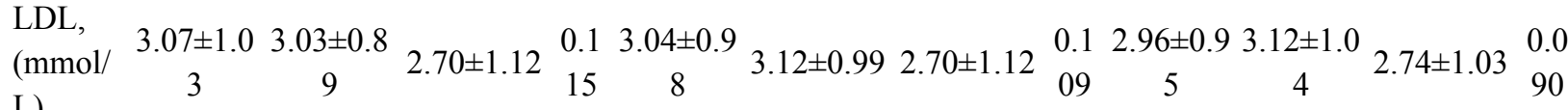
L)

Creatini $\begin{array}{lllllllllll}\text { ne, } & 107.99 \pm 160.39 \pm 1 & 240.24 \pm 2 & <0 . & 117.46 \pm & 153.06 \pm 1 & 240.24 \pm 2<0 . & 96.98 \pm 8 & 127.83 \pm & 235.34 \pm 2 & <0 .\end{array}$

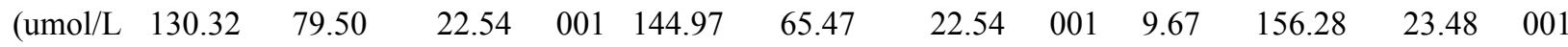
)

$\mathrm{BNP}, \quad 321.89 \pm 859.82 \pm 1 \quad 1767.32 \pm<0 . \quad 345.03 \pm 1056.86 \pm 1767.32 \pm<0 . \quad 235.44 \pm 605.84 \pm 1562.49 \pm<0$.

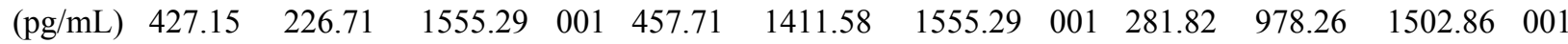




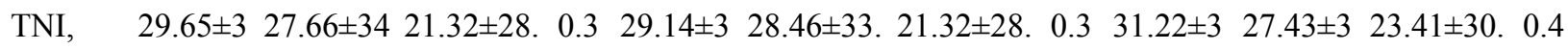
$\begin{array}{lllllllllllll}(\mathrm{ng} / \mathrm{mL}) & 3.42 & .39 & 58 & 41 & 3.57 & 39 & 58 & 59 & 4.43 & 2.82 & 72 & 86\end{array}$

1

2

3 Table 1 Relationships between clinical characteristics and the GPSs in patients with acute 4 myocardial infarction. GPSs = Inflammation-based Glasgow Prognostic Scores; GPS =

5 inflammation-based Glasgow Prognostic Score; MGPS = modified inflammation-based Glasgow

6 Prognostic Score; HS-MGPS = high-sensitivity CRP-modified inflammation-based Glasgow

7 Prognostic Score; HTI-GPS = high tendency interference GPS group; SBP = systolic blood

8 pressure; DBP = diastolic blood pressure; RSN = rank sum number; EF = ejection fraction; ALT

9 = Alanine aminotransferase; $\mathrm{CK}=$ creatine kinase; $\mathrm{CK}-\mathrm{MB}=$ creatine kinase $\mathrm{MB}$; $\mathrm{LDL}=$ low

10 density lipoproteincreatinine; $\mathrm{BNP}=$ type $\mathrm{B}$ natriuretic peptide; $\mathrm{TNI}=$ troponin $\mathrm{I} ; \mathrm{SD}=$ standard

11 deviation. Except for rate and RSN, the rest are represented as mean $\pm \mathrm{SD}$. 


\section{Table 2 (on next page)}

Table 2 Logistic regression analysis of MACE during hospitalization.

Logistic regression analysis of MACE during hospitalization. $\mathrm{OR}=$ odds ratio; $\mathrm{Cl}=$ confidence interval; MACE = Global Registry of Acute Coronary Events; GPS = inflammation-based Glasgow Prognostic Score; MGPS = modified inflammation-based Glasgow Prognostic Score; HS-MGPS = high-sensitivity CRP-modified inflammation-based Glasgow Prognostic Score; GRACE = Global Registry of Acute Coronary Events; $\mathrm{PCl}=$ percutaneous coronary intervention; HTI-GPS = high tendency interference GPS group; SBP = systolic blood pressure; $\mathrm{DBP}=$ diastolic blood pressure; $\mathrm{EF}=$ ejection fraction; $\mathrm{ALT}=$ Alanine aminotransferase; $C K=$ creatine kinase; $C K-M B=$ creatine kinase $M B ; L D L=$ low density lipoproteincreatinine; $B N P=$ type $B$ natriuretic peptide; $T N I=$ troponin $\mathrm{I}$. 


\begin{tabular}{|c|c|c|c|c|c|c|}
\hline \multirow{3}{*}{ Vairable } & \multicolumn{3}{|c|}{ Univariate } & \multicolumn{3}{|c|}{ Multivariate } \\
\hline & OR & analysis for $95 \%$ & $P$ & OR & analysis for $95 \%$ & $P$ \\
\hline & & CI & & & $\mathrm{CI}$ & \\
\hline GPS & & & $<0.001$ & & & $<0.001$ \\
\hline GPS (1 vs 0 ) & 7.806 & $2.954-20.631$ & $<0.001$ & 7.173 & $2.425-21.216$ & $<0.001$ \\
\hline GPS (2 vs 0$)$ & 28.333 & $10.637-75.471$ & $<0.001$ & 18.636 & $5.813-59.746$ & $<0.001$ \\
\hline MGPS & & & $<0.001$ & & & - \\
\hline MGPS (1 vs 0$)$ & 4.292 & $1.708-10.786$ & 0.002 & & & - \\
\hline MGPS (2 vs 0 ) & 16.692 & 7.219-38.598 & $<0.001$ & & & - \\
\hline HS-MGPS & & & $<0.001$ & & & - \\
\hline HS-MGPS ( 1 vs 0 ) & 4.975 & $1.091-22.517$ & 0.038 & & & - \\
\hline HS-MGPS (2 vs 0) & 36.190 & $7.940-164.948$ & $<0.001$ & & & - \\
\hline GRACE score & 1.033 & $1.020-1.046$ & $<0.001$ & 1.019 & $1.004-1.035$ & 0.015 \\
\hline Age & 1.070 & $1.040-1.100$ & $<0.001$ & & & - \\
\hline Males & 0.538 & $0.265-1.094$ & 0.087 & & & 0.746 \\
\hline Hypertension & 0.990 & $0.501-1.956$ & 0.976 & & & 0.291 \\
\hline Diabetics & 2.582 & $1.377-4.841$ & 0.003 & & & 0.079 \\
\hline HTI-GPS & 4.590 & $2.388-8.820$ & $<0.001$ & & & 0.428 \\
\hline PCI type & 0.241 & $0.126-0.463$ & $<0.001$ & & & 0.062 \\
\hline Heart rate & 1.035 & $1.016-1.055$ & $<0.001$ & & & - \\
\hline SBP & 1.001 & $0.990-1.013$ & 0.811 & & & - \\
\hline DBP & 0.969 & $0.944-0.993$ & 0.013 & & & 0.910 \\
\hline Killip class & 6.534 & $3.599-11.861$ & $<0.001$ & & & - \\
\hline
\end{tabular}




\begin{tabular}{|c|c|c|c|c|c|c|}
\hline EF (Simpson) & 0.001 & $0.000-0.070$ & 0.001 & & & - \\
\hline $\mathrm{EF}(\mathrm{M})$ & 0.002 & $0.000-0.183$ & 0.007 & & & 0.655 \\
\hline Hemoglobin & 0.973 & $0.960-0.986$ & $<0.001$ & & & 0.114 \\
\hline Platelet & 0.993 & $0.988-0.998$ & 0.009 & & & 0.133 \\
\hline D-dimer & 1.294 & $1.099-1.523$ & 0.002 & & & 0.501 \\
\hline ALT & 1.002 & $1.000-1.014$ & 0.036 & & & 0.759 \\
\hline CK & 1.000 & $1.000-1.000$ & 0.626 & & & 0.452 \\
\hline CK-MB & 1.001 & 0.999-1.002 & 0.394 & & & 0.805 \\
\hline Albumin & 0.747 & $0.676-0.824$ & $<0.001$ & & & - \\
\hline HS-CRP & 1.015 & $1.009-1.022$ & $<0.001$ & & & - \\
\hline LDL & 0.883 & $0.649-1.203$ & 0.431 & & & 0.706 \\
\hline Creatinine & 1.003 & $1.001-1.005$ & $<0.001$ & & & 0.336 \\
\hline BNP & 1.001 & $1.000-1.001$ & $<0.001$ & 1.000 & $1.000-1.001$ & 0.035 \\
\hline TNI & 1.006 & $0.997-1.016$ & 0.184 & 1.020 & $1.007-1.033$ & 0.003 \\
\hline
\end{tabular}

1 Table 2 Logistic regression analysis of MACE during hospitalization. OR = odds ratio; CI = 2 confidence interval; MACE = Global Registry of Acute Coronary Events; GPS = inflammation3 based Glasgow Prognostic Score; MGPS = modified inflammation-based Glasgow Prognostic 4 Score; HS-MGPS = high-sensitivity CRP-modified inflammation-based Glasgow Prognostic 5 Score; GRACE = Global Registry of Acute Coronary Events; PCI = percutaneous coronary 6 intervention; HTI-GPS = high tendency interference GPS group; SBP = systolic blood pressure; $7 \mathrm{DBP}=$ diastolic blood pressure $\mathrm{EF}=$ ejection fraction; $\mathrm{ALT}=$ Alanine aminotransferase; $\mathrm{CK}=$ 8 creatine kinase; $\mathrm{CK}-\mathrm{MB}=$ creatine kinase $\mathrm{MB}$; $\mathrm{LDL}=$ low density lipoproteincreatinine; $\mathrm{BNP}=$ 9 type $\mathrm{B}$ natriuretic peptide; $\mathrm{TNI}=$ troponin $\mathrm{I}$. 


\section{Table 3 (on next page)}

Table 3 Logistic regression analysis of all-cause mortality during hospitalization.

Logistic regression analysis of all-cause mortality during hospitalization. $\mathrm{OR}=$ odds ratio; $\mathrm{Cl}$ $=$ confidence interval; MACE $=$ Global Registry of Acute Coronary Events; GPS $=$ inflammation-based Glasgow Prognostic Score; MGPS = modified inflammation-based Glasgow Prognostic Score; HS-MGPS = high-sensitivity CRP-modified inflammation-based Glasgow Prognostic Score; GRACE = Global Registry of Acute Coronary Events; $\mathrm{PCI}=$ percutaneous coronary intervention; HTI-GPS = high tendency interference GPS group; SBP = systolic blood pressure; $\mathrm{DBP}=$ diastolic blood pressure; $\mathrm{EF}=$ ejection fraction; $\mathrm{ALT}=$ Alanine aminotransferase; $C K=$ creatine kinase; $C K-M B=$ creatine kinase $M B ; L D L=$ low density lipoproteincreatinine; $\mathrm{BNP}=$ type $\mathrm{B}$ natriuretic peptide; $\mathrm{TNI}=$ troponin I. All values are represented as $\mathrm{OR}(95 \% \mathrm{Cl})$. 


\begin{tabular}{|c|c|c|c|c|c|c|}
\hline \multirow{3}{*}{ Vairable } & \multicolumn{3}{|c|}{ Univariate } & \multicolumn{3}{|c|}{ Multivariate } \\
\hline & OR & analysis for $95 \%$ & $P$ & OR & & $P$ \\
\hline & & $\mathrm{CI}$ & & & $95 \% \mathrm{CI}$ & \\
\hline GPS & & & 0.002 & & & 0.302 \\
\hline GPS (1 vs 0$)$ & 0.791 & $0.147-4.241$ & 0.784 & & & 0.134 \\
\hline GPS (2 vs 0$)$ & 5.495 & $1.810-16.685$ & 0.003 & & & 0.253 \\
\hline MGPS & & & 0.014 & & & - \\
\hline MGPS (1 vs 0 ) & 0.000 & & 0.998 & & & - \\
\hline MGPS (2 vs 0 ) & 4.466 & $1.636-12.194$ & 0.013 & & & - \\
\hline HS-MGPS & & & 0.005 & & & - \\
\hline HS-MGPS (1 vs 0) & 0.916 & $0.161-5.218$ & 0.921 & & & - \\
\hline HS-MGPS ( 2 vs 0 ) & 5.146 & $1.094-24.204$ & 0.038 & & & - \\
\hline GRACE score & 1.044 & $1.022-1.066$ & $<0.001$ & 1.040 & $1.017-1.064$ & 0.001 \\
\hline Age & 1.107 & $1.048-1.170$ & $<0.001$ & & & - \\
\hline Males & 0.785 & $0.265-2.321$ & 0.661 & & & 0.808 \\
\hline Hypertension & 1.111 & $0.379-3.253$ & 0.848 & & & 0.908 \\
\hline Diabetics & 1.242 & $0.480-3.215$ & 0.655 & & & 0.813 \\
\hline HTI-GPS & 3.936 & $1.423-10.887$ & 0.008 & & & 0.499 \\
\hline PCI type & 0.155 & $0.060-0.404$ & $<0.001$ & 0.236 & $0.089-0.625$ & 0.004 \\
\hline Heart rate & 1.027 & $1.002-1.052$ & 0.032 & & & - \\
\hline SBP & 0.991 & $0.972-1.010$ & 0.331 & & & - \\
\hline DBP & 0.956 & 0.919-0.996 & 0.029 & & & 0.696 \\
\hline Killip class & 1.928 & $1.214-3.060$ & 0.005 & & & - \\
\hline
\end{tabular}




\begin{tabular}{|c|c|c|c|c|}
\hline EF (Simpson) & 0.000 & $0.000-0.033$ & 0.002 & - \\
\hline $\mathrm{EF}(\mathrm{M})$ & 0.003 & $0.000-0.814$ & 0.042 & 0.328 \\
\hline Hemoglobin & 0.980 & 0.964-0.997 & 0.019 & 0.907 \\
\hline Platelet & 0.997 & 0.990-1.005 & 0.462 & 0.309 \\
\hline D-Dimer & 1.113 & $1.027-1.205$ & 0.009 & 0.098 \\
\hline ALT & 1.001 & $0.999-1.002$ & 0.584 & 0.644 \\
\hline CK & 1.000 & $1.000-1.000$ & 0.583 & 0.707 \\
\hline CK-MB & 1.000 & $0.998-1.003$ & 0.945 & 0.358 \\
\hline Albumin & 0.802 & $0.716-0.898$ & $<0.001$ & - \\
\hline HS- CRP & 1.010 & $1.003-1.017$ & 0.004 & - \\
\hline LDL & 0.908 & $0.560-1.471$ & 0.649 & 0.149 \\
\hline Creatinine & 1.001 & 0.999-1.003 & 0.224 & 0.606 \\
\hline BNP & 1.000 & $1.000-1.001$ & 0.004 & 0.541 \\
\hline TNI & 1.004 & $0.990-1.018$ & 0.590 & 0.412 \\
\hline
\end{tabular}

1 Table 3 Logistic regression analysis of all-cause mortality during hospitalization. OR = odds 2 ratio; $\mathrm{CI}=$ confidence interval; $\mathrm{MACE}=$ Global Registry of Acute Coronary Events; GPS = 3 inflammation-based Glasgow Prognostic Score; MGPS = modified inflammation-based Glasgow 4 Prognostic Score; HS-MGPS = high-sensitivity CRP-modified inflammation-based Glasgow 5 Prognostic Score; GRACE = Global Registry of Acute Coronary Events; PCI = percutaneous 6 coronary intervention; HTI-GPS = high tendency interference GPS group; SBP = systolic blood 7 pressure; $\mathrm{DBP}=$ diastolic blood pressure; $\mathrm{EF}=$ ejection fraction; $\mathrm{ALT}=$ Alanine 8 aminotransferase; $\mathrm{CK}=$ creatine kinase; $\mathrm{CK}-\mathrm{MB}=$ creatine kinase $\mathrm{MB}$; LDL = low density 9 lipoproteincreatinine; $\mathrm{BNP}=$ type $\mathrm{B}$ natriuretic peptide; $\mathrm{TNI}=$ troponin $\mathrm{I}$. All values are 10 represented as $\mathrm{OR}(95 \% \mathrm{CI})$. 


\section{Table 4 (on next page)}

Table 4 ROC analysis of in-hospital MACE for subgroups.

ROC analysis of in-hospital MACE for subgroups. ROC = receiver operating characteristic;

MACE $=$ Global Registry of Acute Coronary Events; GPS = inflammation-based Glasgow Prognostic Score; MGPS = modified inflammation-based Glasgow Prognostic Score; HS-MGPS = high-sensitivity CRP-modified inflammation-based Glasgow Prognostic Score. AUC = area under the curve; $\mathrm{Cl}=$ confidence interval; STEMI = ST-segment elevation myocardial infarction; NSTEMI = non-ST-segment elevation myocardial infarction; HTI-GPS = high tendency interference GPS group; LTI-GPS = low tendency interference GPS group; $P C I=$ percutaneous coronary intervention; $\mathrm{PPCl}=$ primary $\mathrm{PCl} ; \mathrm{EPCl}=$ elective $\mathrm{PCl}$. All values are represented as AUC $(95 \% \mathrm{Cl})$. 


\begin{tabular}{|c|c|c|c|c|c|c|c|c|c|}
\hline \multirow{2}{*}{\multicolumn{2}{|c|}{ Subgroup AUC }} & \multicolumn{2}{|l|}{ GPS } & \multicolumn{3}{|c|}{ MGPS } & \multicolumn{3}{|c|}{ HS-MGPS } \\
\hline & & $\mathrm{CI}$ & $P$ & AUC & $\mathrm{CI}$ & $P$ & AUC & $\mathrm{CI}$ & $P$ \\
\hline STEMI & 0.7870 & $88-0.887$ & $<0.001$ & \multicolumn{3}{|c|}{$0.7400 .628-0.852<0.001$} & \multicolumn{3}{|c|}{$0.7580 .656-0.861<0.0$} \\
\hline NSTEMI & $0.855 c$ & $72-0.938$ & $<0.001$ & \multicolumn{3}{|c|}{$0.8380 .746-0.931<0.001$} & \multicolumn{3}{|c|}{$0.8120 .719-0.906 \underset{0.0}{<0}$} \\
\hline HTI-GPS & 0.7110 & ;91-0.832 & 0.002 & \multicolumn{3}{|c|}{$0.7170 .596-0.8370 .001$} & \multicolumn{3}{|c|}{$0.6610 .534-0.7877_{8}^{0.01}$} \\
\hline LTI-GPS & 0.797 & $579-0.915$ & $<0.001$ & \multicolumn{3}{|c|}{$0.7020 .563-0.8410 .003$} & \multicolumn{3}{|c|}{$0.7650 .647-0.883<0.0$} \\
\hline PPCI & $0.800 c$ & $707-0.893$ & $<0.001$ & \multicolumn{3}{|c|}{$0.7560 .649-0.863<0.001$} & \multicolumn{3}{|c|}{$0.7750 .682-0.868 \underset{0.0}{<0}$} \\
\hline EPCI & $0.750 c$ & $142-1.000$ & 0.134 & \multicolumn{3}{|c|}{$0.7830 .493-1.000 \quad 0.089$} & \multicolumn{3}{|c|}{$0.7000 .419-0.9810 .23$} \\
\hline Non-PCI & 0.7160 & $32-0.900$ & 0.030 & \multicolumn{3}{|c|}{$0.6920 .509-0.8760 .053$} & \multicolumn{2}{|c|}{$0.7140 .533-0.896^{0}$} & $\begin{array}{c}0.03 \\
1\end{array}$ \\
\hline
\end{tabular}

1 Table 4 ROC analysis of in-hospital MACE for subgroups. ROC $=$ receiver operating 2 characteristic; MACE = Global Registry of Acute Coronary Events; GPS = inflammation-based 3 Glasgow Prognostic Score; MGPS = modified inflammation-based Glasgow Prognostic Score; 4 HS-MGPS $=$ high-sensitivity CRP-modified inflammation-based Glasgow Prognostic Score. $5 \quad \mathrm{AUC}=$ area under the curve; $\mathrm{CI}=$ confidence interval; STEMI $=$ ST-segment elevation 6 myocardial infarction; NSTEMI = non-ST-segment elevation myocardial infarction; HTI-GPS = 7 high tendency interference GPS group; LTI-GPS = low tendency interference GPS group; $\mathrm{PCI}=$ 8 percutaneous coronary intervention; $\mathrm{PPCI}=$ primary PCI; EPCI $=$ elective $\mathrm{PCI}$. All values are 9 represented as AUC $(95 \% \mathrm{Cl})$. 